\title{
Preparation and Characterization of Silica Gel from Wheat Straw
}

\author{
Khushbu G. Patel, Nirendra M. Misra, and Rakshith R. Shettigar
}

\begin{abstract}
Silica gel was prepared by using alkaline extraction and acid neutralization method from ash obtained wheat straw, an agricultural waste. Microwave digestion, followed by calcination was used for obtaining ash. X-ray diffractometry (XRD) and Fourier transform infrared spectroscopy (FTIR) studies revealed the ash to be mostly amorphous silica. Alkaline-solubilization and acidneutralization method was used to obtain gel from silica obtained from wheat straw.

Gel was characterized using FTIR. Nitration reaction of benzaldehyde using the silica gel (as acid catalyst) and copper nitrate was successfully carried out.
\end{abstract}

Index Terms - Wheat straw, amorphous silica, silica gel, nitration.

\section{INTRODUCTION}

Utilization of waste including agricultural waste is need of the hour. One of the major agricultural wastes is wheat straw. About 600 million tons of wheat is produced around the world annually [1]. Dry stalks of wheat plant after removal of grains are known as wheat straw. It contains in carbon, oxygen, potassium, silica, and low levels of aluminum, magnesium, sodium phosphorous, and sulphur [2].

TABLE I: CHEMICAL COMPOSITION OF WHEAT STRAW [3], [4]

\begin{tabular}{cc}
\hline Components & Percentage $(\%)$ \\
\hline Dry matter & 89 to 94 \\
Acid detergent fiber & 54 \\
Cellulose & 33.5 to 40 \\
Hemicellulose & 21 to 26 \\
Lignin & 11 to 23 \\
Ash & 7 to 9.9 \\
Silica and silicates & 4.5 to 5.5 \\
Crude protein & 3.6 \\
Calcium & 0.2 \\
Phosphorus & 0.05 \\
\hline
\end{tabular}

Wheat straw and wheat husk are being used also as fuel due to their high calorific value. Wheat husk ash contains $10-12 \%$ silica in complex form and $80-90 \%$ silica in amorphous form [5].

Silica in its amorphous form has huge industrial applications. It can be used in coatings, detergents, rubber industry, plastics manufacturing, electronics, abrasives, refractory, and optics and also used as a catalyst in organic reactions [6]. Silica gel has been widely used in

Manuscript received November 26, 2015; revised February 23, 2016.

The authors are with the Department of Sciences, School of Technology (SOT), Pandit Deendayal Petroleum University, Gandhinagr, Gujarat, India (e-mail: info@pdpu.ac.in) pharmaceuticals and industrial applications like purification and dehydration of hazardous gases in industry, desulphurization of motor oil, petroleum refining, distillations, oil hydrogenation process, use as a catalyst in sulphuric acid production and also use as a grain drying absorbent [7].

Generally, silica gel is prepared from commercially available sodium silicate. The manufacturing process of sodium silicate from quartz sand with calcium carbonate is very expensive due to high temperature requirement [8], [9].

Silica gel prepared from rise husk ash has been reported by many authors [10]-[12]. 'Nayak et al.' successfully produced humidity indicating silica gel from rice husk ash using alkaline-solubilization and acidic neutralization methods [13]-[16].

In the present work, silica gel was prepared from agricultural waste - wheat straw. Alkaline-solubilization and acid-neutralization method was used to obtain gel from silica obtained from wheat straw. The methods and materials were explained as below.

\section{MATERIALS AND METHODS}

\section{A. Materials}

Wheat straw (collected from local agricultural field), $1 \mathrm{~N}$ sodium hydroxide (Merck), 1N Hydrochloric acid. (QualiKems).

\section{B. Methods}

Wheat straw was treated with hydrochloric acid in a microwave digester. Acid treated product after removal of excess acid was calcined $550^{\circ} \mathrm{C}$. Fine white powder was obtained after calcination.

Ash obtained after calcination was characterized by XRD and FTIR.

The obtain gel, each time about $1 \mathrm{~g}$ of the white powder (ash) was taken in round bottom flask and treated with $100 \mathrm{ml}$ of $1 \mathrm{~N} \mathrm{NaOH}$ solution. Mixture was refluxed for $1 \mathrm{hr}$ with constant stirring.

After bringing down the reaction mixture to room temperature it was filtered using Whatman no.42 to remove solid residue. Hardly any residue was noticed over the filter paper.

Filtrate was treated with $1 \mathrm{~N} \mathrm{HCl}$. It was added drop wise to maintain $\mathrm{pH}$ above 7. Precipitation occurred and a gel was formed. Gel formation was observed only when the $\mathrm{pH}$ of the mixture was between 7 and 10 .

The suspension was centrifuged for $15 \mathrm{~min}$ at $4000 \mathrm{rpm}$ to remove excess liquid. The semi-solid (gel) mass obtained after decantation was characterized by FTIR. 


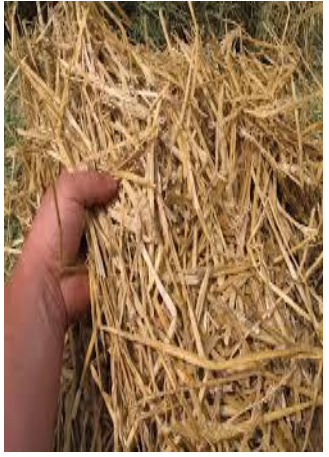

(a)

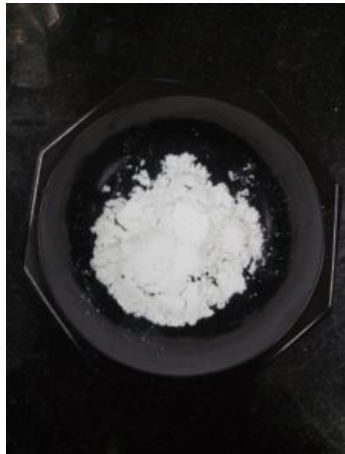

(b)

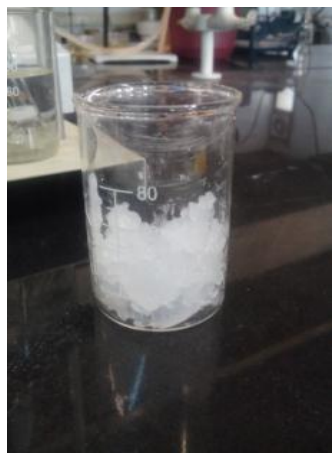

(c)

Fig. 1. (a) Wheat straw (b) Silica containing white ash (c) Silica gel.

\section{Flow Chart of Silica Gel Production}

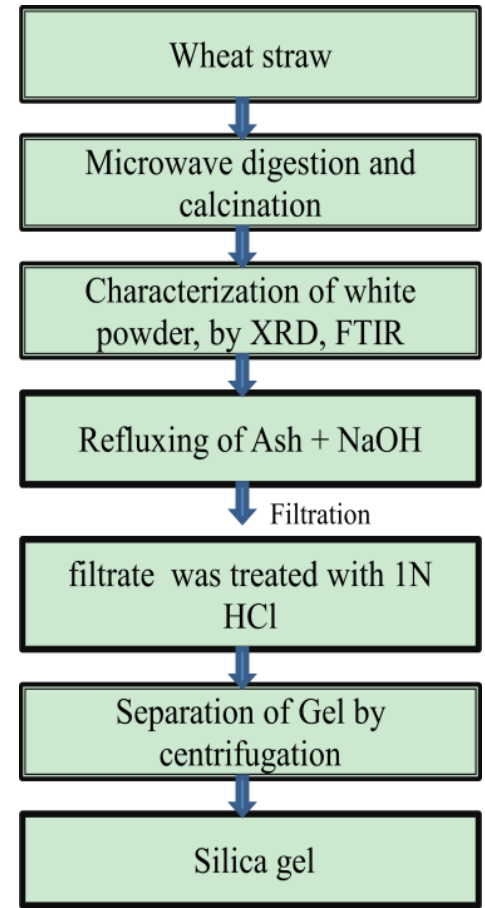

Fig. 2. Flow diagram of silica gel preparation from wheat straw.

Wheat straw which collected from local agricultural field was digesting in microwave digester for 10-15 minutes than charred product calcined in muffle furnace at $550^{\circ} \mathrm{C}$ for $4 \mathrm{hrs}$, obtained white powder characterized by XRD and FTIR. This white powder treated with $\mathrm{NaOH}$ reflux for $1 \mathrm{hr}$. After acid-neutralization method, the gel was obtained after few minutes. After centrifuge process silica gel was obtained. The product was characterized by XRD and FTIR.

\section{RESULT AND DISCUSSION}

\section{A. Reaction Mechanism}

Following reaction takes place between $\mathrm{SiO}_{2}$ and $\mathrm{NaOH}$, [14]-[16].
(White (Sodium

Ash)
$\mathrm{SiO}_{2}+2 \mathrm{NaOH}$

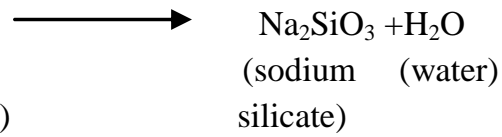
silicate)
Sodium silicate upon treatment with $\mathrm{HCl}$ forms silica gel, $\begin{array}{clc}\mathrm{Na}_{2} \mathrm{SiO}_{3}+\mathrm{HCl} \longrightarrow & \mathrm{SiO}_{2}+\mathrm{NaCl}+\mathrm{H}_{2} \mathrm{O} \\ \text { (Sodium } & \text { (Hydrochloric } & \text { (Silica) (sodium (Water) } \\ \text { Silicate) } & \text { acid) } & \text { chloride) }\end{array}$

B. Characterization of Silica Containing White Ash and Silica Gel

X-ray diffractogram (Pananalytical, model - Xpert Pro) of white powder white powder, obtained after calcination, gave a wide band at $2 \theta=22^{\circ}$ which clearly indicate that the material was amorphous in nature.

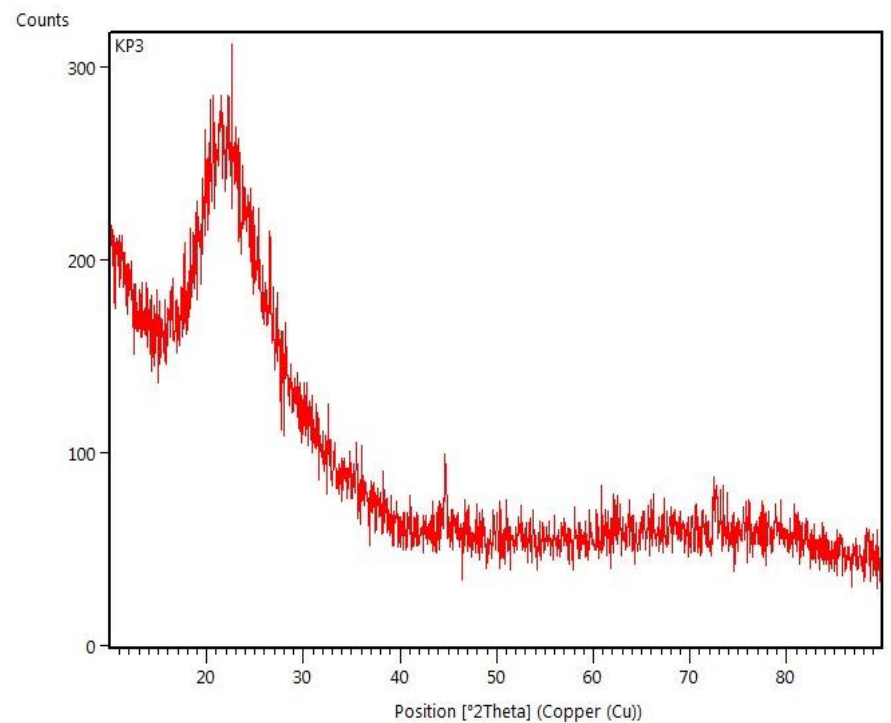

Fig. 3. XRD of silica containing white ash.

The material of silica containing white powder and the gel was characterized by PerkinElmer Spectrum Version 10.4.2 FTIR (Furrier transformer infrared technology).

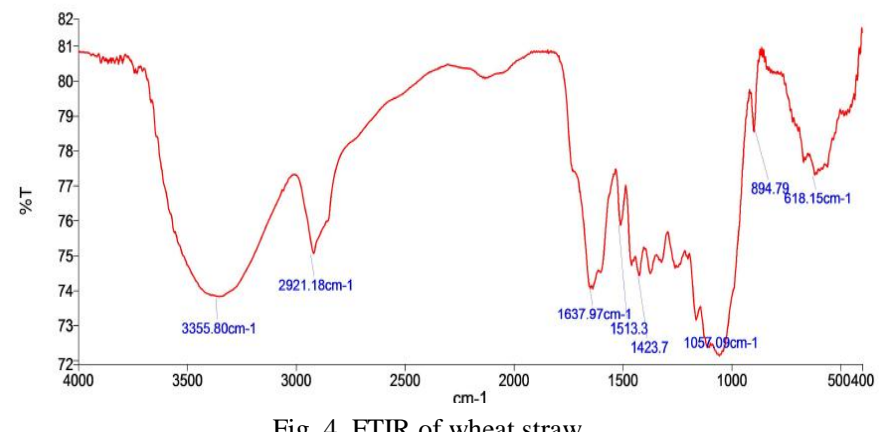

Fig. 4 shows presence of large amount of silica was present in surface of wheat straw with wave number $1057.09 \mathrm{~cm}-1$. The wave number $3355.8 \mathrm{~cm}^{-1}$ indicates $-\mathrm{OH}$ 
was present on surface of wheat straw. The cellulose and lignin are in the inner and middle layer of wheat straw gives a wave number in between $1600 \mathrm{~cm}^{-1}$ to $1000 \mathrm{~cm}^{-1}$ The FTIR spectrum in Fig. 5 shows that the IR bands at $794 \mathrm{~cm}^{-1}$ and $1080 \mathrm{~cm}^{-1}$ can be indicated to the asymmetric and symmetric stretching vibrations of the $\mathrm{Si}-\mathrm{O}-\mathrm{Si}$ linkages of the $\mathrm{SiO}_{2}$ framework.

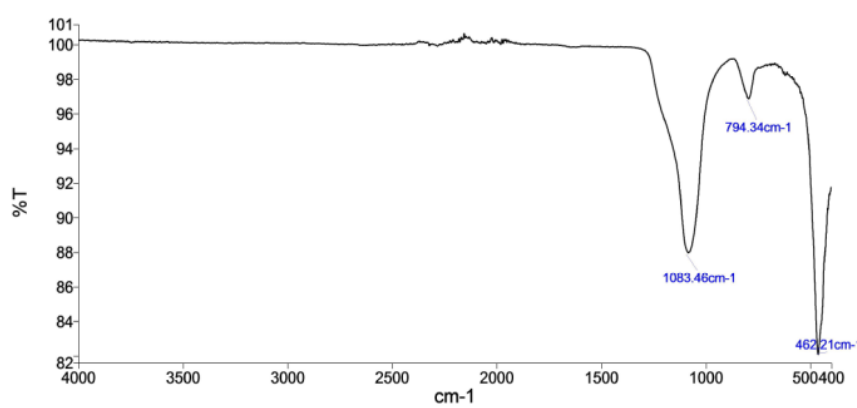

Fig. 5. FTIR of silica containing white ash.

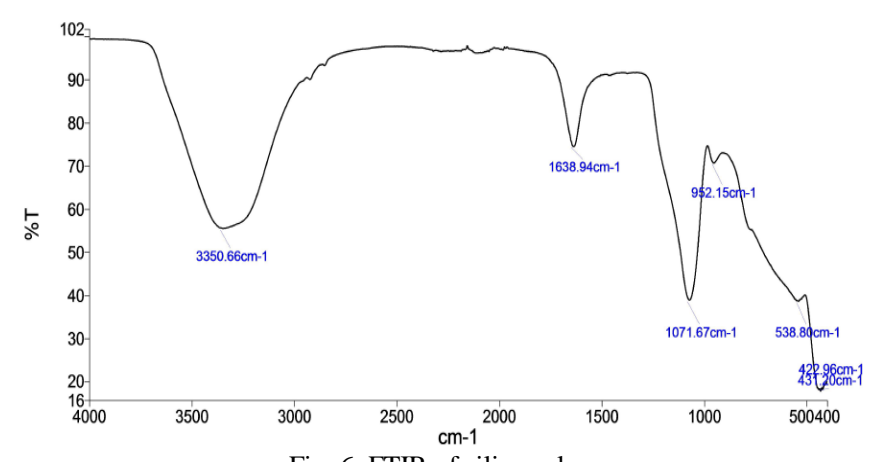

Fig. 6. FTIR of silica gel.

Strong and broad absorbance $\mathrm{O}-\mathrm{H}$ stretching band is seen at wave number of $3350.6 \mathrm{~cm}^{-1}$ in Fig. 6. A weaker $\mathrm{O}-\mathrm{H}$ bending vibration band is seen at $1638 \mathrm{~cm}^{-1}$. The $\mathrm{Si}-\mathrm{O}-\mathrm{Si}$ vibration gives the strong band at $1071 \mathrm{~cm}^{-1}$ is clearly indicating silica gel formation [17], [18].

\section{Application}

Silica gel finds numerous applications as adsorbent in chromatographic separation, a mediator, reagent and catalyst in organic synthesis [19]-[25]. 'Khouzani et al.' used silica gel as catalyst in synthesis of quinopthalone by using microwave irradiation under solvent free condition [26]. Malekil et al. used highly efficient and heterogeneous, sulfuric acid immobilized silica gel catalyst for one pot synthesis of imidazole derivatives [27]. Silica gel has been used in cyclization reactions of hetroaromatic compound [28].

In the present work, silica gel obtained from wheat straw was used for a nitration reaction without using nitric acid. 'Hosseini-Sarvari et al.' have successfully discovered a novel method for nitration of phenols, aldehydes and other aromatic compounds in the presence of alumina sulfuric acid (ASA) as a catalyst and $\mathrm{Mg}\left(\mathrm{NO}_{3}\right)_{2} \cdot 6 \mathrm{H}_{2} \mathrm{O}$ as a nitrating agent in neat water as a solvent (Scheme 1). With this protocol nitrated products were obtained in excellent yields [29].

In the application of silica gel, we using $1 \mathrm{mmol}$ cuprous nitrate as a nitrating agent were added in $1 \mathrm{mmol}$ benzaldehyde, silica gel was adding as mild acid catalyst and $1 \mathrm{ml}$ water use as a solvent [30]. The reaction mixture kept under the microwave reactor at $80^{\circ} \mathrm{C}$ for $10 \mathrm{~min}$. The most probable reaction mechanism is show in Scheme 2.

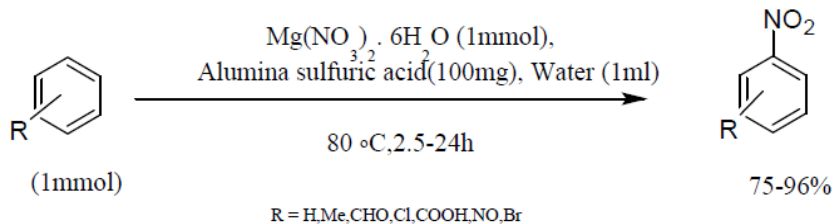

Scheme 1. Nitration of aromatic compounds catalyzed by ASA.
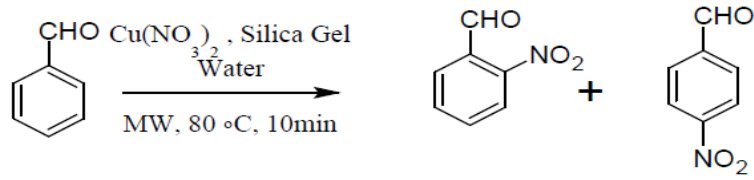

Scheme 2. Nitration of aldehydes compound catalyzed by wheat strawsilica gel.

The reaction was monitored by thin layer chromatography and FTIR spectrum of product in Fig. 7.

Thin layer chromatography shows two yellowish spots of product and starting material was absent, it's conform that reaction was gone successfully and excellent yield was obtained. FTIR study also shows that reaction goes successfully and good yield was obtained.

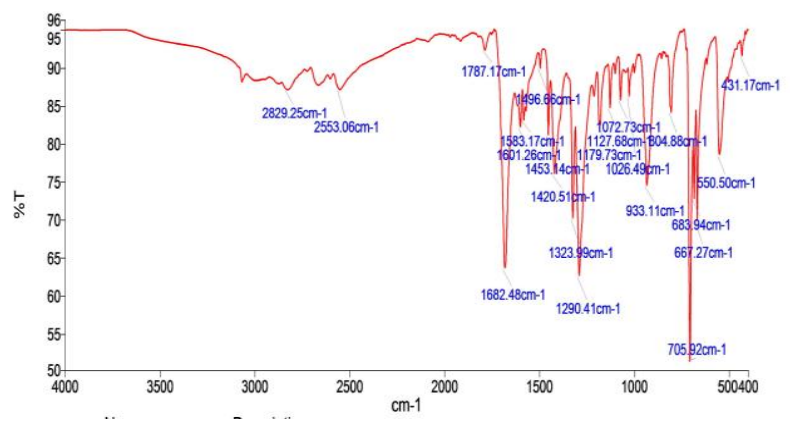

Fig. 7. FTIR of product nitro benzaldehyde.

\section{CONCLUSION}

The study showed that amorphous silica of high purity can be obtained from an agricultural waste- wheat straw. This silica can also be used to prepare silica gel through microwave assisted reaction in a short span of time. In one of the applications of silica-gel it was demonstrated that nitration of benzaldehyde is possible without nitration mixture $\left(\mathrm{HNO}_{3}\right.$ and $\left.\mathrm{H}_{2} \mathrm{SO}_{4}\right)$, through microwave assisted reaction. Silica gel obtained from wheat straw is an effective green catalyst.

\section{ACKNOWLEDGMENT}

We wish to thank 'Leo Nutriscience' Kathwada GIDC, Gujarat, for providing chemical facility.

\section{REFERENCES}

[1] H. Boyacloglu, World Wheat Condition, Feed Management Systems, 2009

[2] A. K. Bledzki, A. A. Mamuna, and J. Volk., "Physical, chemical and surface properties of wheat husk, Rice husk and soft wood and their poly propylene," Composites, vol. 41, issue 4, pp. 480-488, 2010. 
[3] M. Yasin, A. W. Bhutto, A. A. Bazmi, and S. Karim, "Efficient utilization of rice-wheat straw to produce value added composite products," Int. J. Chem. Env. Eng., pp. 136-143, 2010.

[4] S. T. Khan and U. Mubeen, "Wheat straw: A pragmatic overview," Current Research Journal of Biological Sciences, vol. 4, no. 6, pp. 673-675, 2012.

[5] J. S. Zhang, J. M. Khatib, C. Booth, and R. Siddhique, "Possible utilization of wheat husk ash waste in production of precast concrete elements," Excellence in Concrete Construction trough Innovation, 2009.

[6] R. H. McDonald, "Silica in Nova Scotia," Information Circular ME $14,2^{\text {nd }}$ edition, Nova Scotia Department of Natural Resources, Mineral Resources, Government of Nova Scotia, 1991.

[7] E. A. Okoronkwo, E. A. Okoronkwo, P. E. Imoisili, and S. O. O. Olusunle, "Extraction and characterization of Amorphous Silica from Corn- Cob Ash by Sol-Gel Method," Chemistry and Materials Research, vol. 3, no. 4, 2013.

[8] R. K. Iler, Silica Gels and Powders - The Chemistry of Silica, New York: John Wiley and Sons, p. 462, 1979

[9] C. J. Brinker and G. W. Scherer, Sol-gel Science - The Physicsand Chemistry of Sol-gel Processing, New York: Academic Press Inc, pp. 839-880, 1990.

[10] S. R. Kamathand and A. Proctor, "Silica gel from rice hull ash: Preparation and characterization," Cereal Chem., vol. 75, pp. 484-493, 1990.

[11] U. Kalapathy, A Proctor, and J. Shultz, "A simple method for production of pure silica from rice hull ash," Bioresource Technology, vol. 73, pp. 257-264, 2000.

[12] U. Kalapathy, A. Proctor, and J. Shultz, "An improved method for production of silica from rice hull ash," Bioresource Technology, pp. 285-289, 2002.

[13] J. P. Nayak and B. E. R. A. Japes, "Preparation of an efficient humidity indicating silica gel from rice husk ash," Bull. Mater. Sci., vol. 34, no. 7, pp. 1683-1687, Indian Academy of Sciences, December 2011.

[14] C. B. Majumdar, M. Sharma, and G. Soni, "The simple nonconventional method to extract amorphous silica from rise husk," Bio Resource Technology, 2014.

[15] N. J. Shamle, C. J. Dados, S. E. Iwoh, J. G. Nangbes, and A. U. Awode, "Comparative assessment of the yields of silica from husk ashes of digitariaexilis (acha), wheat and rice," IOSR Journal of Applied Chemistry (IOSR-JAC), vol. 7, issue 7, ver. III, pp. 01-04, 2014.

[16] G. V. Rao and B. P. Harry, "Regeneration capacity of silica gel for grain drying," Agency for International Development United States Department of State, April, 1974.

[17] L. J. Foschiera, M. Tania, T. M. Pizzolat, and E. V, Benvenutti, "Thermal analysis on organo functionalized silica gel," J. Braz. Chem. Soc., 2001, vol. 12, no. 2, pp. 159-164.

[18] U. Vijayalakshmi, A. Balamurugan, and S. Rajeswari, "Synthesis and characterization of porous silica gels for biomedical applications," Trends Biomater. Artif. Organs, vol. 18, no. 2, January 2005.

[19] O. Satoaki, Z. J. Yong, S. C. Ajam, F. Hiroshi, and I. Junji, "Silica gel-mediated organic reactions under organic solvent-free conditions," Molecules, vol. 17, pp. 11469-11483, 2012.

[20] D. Francis and A. M. Tius, "Interrupted nazarov cyclization on silica gel," J. Am. Chem. Soc., vol. 127, pp. 12472-12473, 2005.

[21] S. Gae"llel, R. Andrzej, and R. Suchada, "Efficient synthesis of tricyclic benzobisoxazines by silica gel catalysis," J. Org. Chem., 2007, vol. 72, pp. 1867-1869.
[22] T. Tsuyoshi and P. Dennis Curran, "Silica gel promotes reductions of aldehydes and ketones by N-heterocyclic carbeneboranes," Organicletters, 2012, vol. 14, no. 17, pp. 4540-4543.

[23] W. Junhua, Y. Zhenle, N. Renfeng, H. Zhaoyin, and Z. Xiaoming, "Hydrogenation of nitrobenzene to aniline over silica gel supported nickel catalysts," Ind. Eng. Chem., vol. 49, pp. 4664-469, 2010.

[24] M. E. González-Núñez, R. Mello, A. Olmos, and G. Asensio, "Baeyer-villiger oxidation with potassium peroxomonosulfate supported on acidic silica gel," J. Org. Chem., vol. 70, pp. 10879$10882,2005$.

[25] N. Partha, L. D. James, B. Philip, and J. E James, "Preparation of diphenyl phosphide and substituted phosphines using alkali metal in silica gel (M-SG)," Organicletters, vol. 11, no. 8, pp. 1689$1692,2009$.

[26] K. L. Hossein, S. M. Majid M. Sadeghi, and J. Safari, "Silica gel catalyzed synthesis of quinophthalone pigments under solvent-free conditions using microwave irradiation," Molecules, vol. 7, pp. 135$139,2002$.

[27] M. Behrooz, S. K. Hossein, T. Fereshteh, and A. Elahe, "Sulfuric acid immobilized on silica gel as highly efficient and heterogeneous catalyst for the one-pot synthesis of 2,4,5-triaryl-1h-imidazoles,' International Journal of Organic Chemistry, pp. 93-99, 2012.

[28] A. K. Banerjee, M. S. LayaMimo', and W. J. V. Vegas, "Silica gel in organic synthesis," Russian Chemical Reviews, vol. 70, no. 11, pp. $971 \pm 990,2001$.

[29] M. Hosseini-Sarvari, M. Tavakolian, and S. Ashenagar, "Nitration of aromatic compounds using alumina sulfuric acid (ASA) as a novel heterogeneous system and $\mathrm{Mg}\left(\mathrm{NO}_{3}\right)_{2} \cdot \mathrm{H}_{2} \mathrm{O}$ asnitrating agent in water," Iranian Journal Of Science \& Technology, Transaction A, vol. 34, no. A3, The Islamic Republic of Iran, 2010.

[30] Y. Urvashi, M. Hemant, and G. Prasanna, "Nitration of phenols using $\mathrm{Cu}\left(\mathrm{NO}_{3}\right)_{2}$ : Green chemistry laboratory experiment," J. Chem. Educ., vol. 89 , pp. 268-270, 2012.

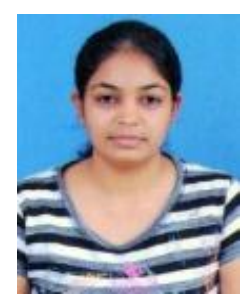

Khushbu G. Patel is pursuing Ph.D. studies in Pandit Deendayal Petroleum University, Gandhinagar. She was born on $9^{\text {th }}$ May, 1990 in Amreli, a coastal city of Gujarat State, India. She is a post graduate in M.Sc. degree in chemistry from Gujarat University, Ahmedabad, Gujarat, India in the year of 2012. She completed his B.Sc. in the year 2010 from Gujarat University, Gujarat, India.

Her professional experience includes $R \& D$ chemist in Parshwanath Dye chemicals Pvt. Ltd. Ahmedabad, Gujarat, India. Her research areas of interest are green chemistry, catalyst and catalytic activity, organic synthesis.

Her recent publications include "Eco-friendly extreme pressure lubricants for water based drilling fluids" by Rakshith R Shettigar, Nirendra M. Misra, Bhaskar Naik, Khushbu Patel, International Conference on Environment, Chemistry and Biology held on 19-21 November 2015 at Auckland, New Zealand. "Recent advances in the synthesis of zeolite from fly ash", by Khushbu Patel, V. K. Srivastava; published in International Journal of Research and Scientific Innovation (IJRSI). 
